\title{
Editorial
}

\section{Book Lovers, Technophiles, Pragmatists, and Printers}

Does this sound like a song title to you? For some reason, Cher's Gypsies, Tramps, and Thieves pops into my head. But no, it is the title of an upcoming article in our journal by Andy Revelle, Kevin Messner, Aaron Shrimplin, and Susan Hurst - all from Miami University in Ohio. It is an interesting study about how different types of academic library patrons ("opinion types") approach the acceptance and use of e-books. We accepted this article for publication almost a year ago, but it will not see official print publication until our next issue in September 2012. Why the delay? CERL, like most print based journals, has paper page limitations that allow us to print only about five articles per issue. We accept new articles at a faster rate, and over time a backlog develops, in our case, about a year backlog.

We found a solution for making this backlog of accepted articles accessible by establishing an online preprint service several years ago. Now accepted articles, like "Book Lovers, Technophiles, Pragmatists, and Printers: the Social and Demographic Structure of User Attitudes Toward E-books," in its final manuscript form, short of only proof editing, sees the light of day shortly after its acceptance. You can find all the journal's online preprints - more than thirty-five of them - by going to the CERL Web site at http://crl. acrl.org/. I recommend bookmarking this web site and becoming familiar with its services. Not only will you find preprints, but online access to the current issue, all articles back to 1996, and use-

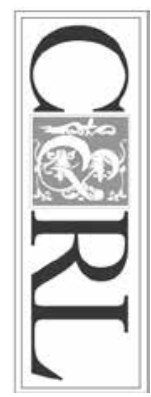
ful alert service options. Set

up RSS feeds or e-mail alerts to find out right away what new tables of contents, articles, and preprints are released by $C \mathcal{E R L}$. It is easy to do.

Right now the only thing you cannot find on the CERL website is the print back file of the journal's articles from 1939 to 1995 , but that is soon to change. Thanks to the good and generous effort of the University of Illinois Libraries, this CERL print back file has been digitized, and within months will be available online. Then you will have complete online, open access to everything past and present from CERL.

Soon, too, the print based nature of $C \mathcal{E} R L$ will change. Discussions and planning are underway by the journal's editorial board and by our parent organization, ACRL, to move the journal to an online only journal. The target date for this transition is only a year-and-a-half away - the end of 2013. Then paper print limitations will go away, but so will the familiar and handy bi-monthly print issue of $C \mathcal{E} R L$. How will we best connect with our readers in this totally online environment? How can we make the online journal and its website more attractive, interactive, and richer in content? We welcome your suggestions. Send your ideas to me (joseph.branin@kaust.edu. sa) or any members of our editorial team and board. Our names are listed on the journal masthead. You can also "contact us" from the CERL website. 